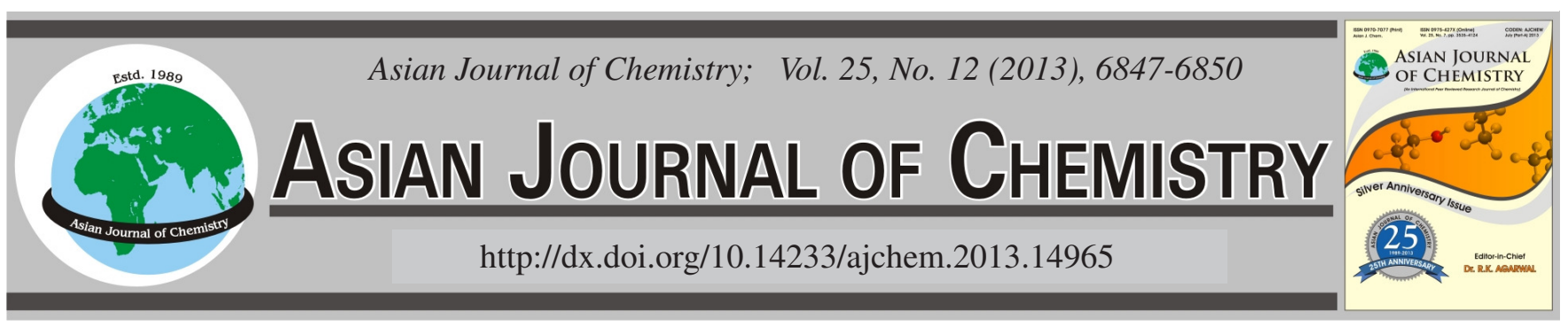

\title{
Adsorption of Lead and Methylene Blue by Oudemansiella radicata
}

\author{
Nan HE ${ }^{\dagger}$, YingYi LiU ${ }^{\dagger}$, Bo Li, JuAn Jiang and Heng Xu*
}

Key Laboratory of Bio-resources and Eco-environment of Education Ministry, College of Life Science, Sichuan University, Chengdu 610064, P.R. China

*Corresponding author: Fax: +86 28 85418262; Tel: +8628 85414644; E-mail: xuheng64@ sina.com

$\dagger$ These authors contributed equally to this work.

Oudemansiella radicata was employed as an adsorbent to adsorb lead and methylene blue from aqueous solution. Response surface methodology and mixture design were both applied to exploring the competitivity and different ratio between lead and methylene blue. The results showed that lead had an obvious inhibition to methylene blue, but methylene blue had little effect on lead on the contrary. The isotherm and kinetic analysis presented that the Freundlich model can explain the adsorption of lead in both single and mixture system and methylene blue only in mixture system. The pseudo-second-order kinetic model best described the kinetic of the adsorption process of lead and methylene blue in single and mixture system. The adsorption of methylene blue also fitted Elovich kinetic model.

Key Words: Oudemansiella radicata, Response surface methodology, Lead, Methylene blue, Adsorption.

ᄂ - - - - - - - - - - - - - - - - - - - - - - - - - - - -

\section{INTRODUCTION}

As known, heavy metal such as $\mathrm{As}, \mathrm{Cr}, \mathrm{Cu}, \mathrm{Co}, \mathrm{Pb}, \mathrm{Ni}$ and $\mathrm{Zn}$ are always used to stabilize the colour of dyes. Therefore, the waste water produced by many industries like textile, cosmetics, pater, food, leather and cottons contains both dyes and heavy metals ${ }^{1}$. Dyes and heavy metals are both toxic and carcinogenic ${ }^{2,3}$ to human beings. So it is urgent to remove dyes and heavy metal from such kind of aqueous effluents.

A number of conventional methods are employed to dealing with dye and heavy metal waste water, like chemical precipitation, electroflotation, reverse osmosis and ion exchange for heavy metal removal and photocatalysis, filtration, oxidation and microbiological decomposition for decolorization ${ }^{4}$. Among these technologies, adsorption is widely applied in both dyes and heavy metal removal for high efficiency, easy operation and low cost. As reported, many agricultural and industrial by-product were studied as adsorbents for dyes and heavy metal removal, such as wheat straw ${ }^{5,6}$, zeolite , Candida tropicalis $^{8}$.

In this study, Oudemansiella radicata was chosen as adsorbent and lead and methylene blue contaminated water as wastewater. lead and methylene blue have been selected for adsorption studies for many researches. But no study has been carried out using Oudemansiella radicata. Futhermore, $O$. radicata is cultivated widely in China. Therefore, it is a good choice to use it as ecofriendly and inexpensive source of readily available adsorbent.
In this study, batch experiments were designed to study the competitivity between lead and methylene blue and the experiments was carried out by response surface methodology. Langmuir, Freundlich and Temkin sorption isotherms were used to describe adsorption equilibrium data. Three kinetic models have been used to analyze the adsorption process.

\section{EXPERIMENTAL}

Fresh spent mushroom of $O$. radicata which was purchased from Huike, a mushroom production base in Chengdu of China, was used in this study as the adsorbent. The mud was removed by a knife and washed with ultrapure water for 3-5 times to remove dirt. After these steps, the biomass was dried at $50{ }^{\circ} \mathrm{C}$ for $24 \mathrm{~h}$, then was ground into fine powder by a pulverizing machine (Joyoung, China). In the last, it was sieved through a 200-mesh stainless steel sieve. Stock metal and dye solutions were prepared by dissolving appropriate amounts of $\mathrm{Pb}\left(\mathrm{NO}_{3}\right)_{2}$ (s) and methylene blue (KeLong Chemical Reagent Factory, China) in ultrapure water. The required working solutions of lead and methylene blue for the adsorption experiments were obtained by diluting each stock solution.

All the chemical reagents used in this study were analytical grade and all the solutions were prepared using ultrapure water. Measurement of $\mathrm{pH}$ was conducted utilizing a $\mathrm{pH} / \mathrm{mV}$ handheld meter (PHB, China).

Metal uptake procedure: Batch experiments were carried out at $25^{\circ} \mathrm{C}$ in $150 \mathrm{~mL}$ Erlenmeyer flasks containing 
$50 \mathrm{~mL}$ metal solutions by shaking $0.4 \mathrm{~g}$ of SAB at $150 \mathrm{rpm}$ (Shaker incubator, SUKUN, China) for $2 \mathrm{~h}$ until equilibrium was reached. After the biosorption process, the samples were filtered immediately to remove the biosorbent by vacuum filtration using filter paper (Whatman, China).

Metal analysis method: The analysis of vestigial lead in aqueous solution was performed by the flame atomic absorption spectrophotometer (VARIAN, America) with an oxidizing air acetylene flame and background correction of the deuterium lamp. The analysis of vestigial methylene blue in solution was using visible spectrophotometer at $665 \mathrm{~nm}$.

Calculation and data analysis method: The metal concentrations sorbed by adsobent were calculated from the difference between the initial and the final metal and dye concentrations $\left(\mathrm{C}_{\mathrm{i}}\right.$ and $\left.\mathrm{C}_{\mathrm{eq}}\right)$ in solution. The following equations were used to compute the removal percentage and the specific uptake by the sorbent, $\mathrm{q}_{\mathrm{eq}}(\mathrm{mg} / \mathrm{g})$, respectively:

$$
\begin{gathered}
\mathrm{Pb}(\mathrm{II}) \text { removal }(\%)=\frac{\mathrm{C}_{0}-\mathrm{C}_{\mathrm{e}}}{\mathrm{C}_{0}} \times 100 \\
\mathrm{q}_{\mathrm{e}}(\mathrm{mg} / \mathrm{g})=\frac{\mathrm{C}_{0}-\mathrm{C}_{3}}{\mathrm{M}}
\end{gathered}
$$

where V (L) is the solution volume and $\omega(\mathrm{g})$ the amount of dry sorbent used. The $\mathrm{pH}$ was measured at the beginning and the end of the experiments. Each experiment was carried out in triple and the average results are presented.

The collected data was analyzed using Statistical Package for the Social Sciences (SPSS) 16 statistical software for the evaluation.

Sorption kinetics and isotherm experiments: Kinetics experiments were performed to determine the necessary of contact time to reach equilibrium. Different Erlenmeyer flasks were treated following the general procedure described above and the samples were taken at predetermined time intervals ranging from 5 to $240 \mathrm{~min}$. The initial metal concentration was $120 \mathrm{mg} / \mathrm{L}$ and $\mathrm{pH}$ of 4 .
For sorption isotherm experiments, the concentration ranges used were $20-120 \mathrm{mg} / \mathrm{L}$. The solution $\mathrm{pH}$ was 4 and the Erlenmeyer flasks were shaken for $2 \mathrm{~h}$.

Response surface methodology: Response surface methodology is a classic experiment design to screen the optimum condition. This experimental design is a useful and convenient method to reduce the times of experiment. But in this study, we use response surface methodology to exploring the competitivity between lead and methylene blue in mixed wastewater.

The mixture design was also employed in this study, which is used to find the effect of the different ratio of lead and methylene blue on their removal percentage.

\section{RESULTS AND DISCUSSION}

Response surface methodology and mixture design: As shown in Table-1, it is not difficult to find that between lead and methylene blue, there have been competitive behaviours. Only lead or methylene blue presence, their adsorption capacity increased only because their initial concentration increases. But when lead and methylene blue exist at the same time, the situation is different. Methylene blue adsorption capacity was inhibited by lead, and it is found that as lead initial concentration increasing, the adsorption capacity of methylene blue decreased. However, adsorption capacity of lead was little affected by methylene blue. As the initial concentration of methylene blue changing, adsorption capacity of lead did not show significantly changes.

Adsorption isotherms: The adsorption equilibrium is usually described by adsorption isotherm model to explore the adsorption mechanism. Three common isotherm models, Langmuir, Freundlich and Temkin models were employed in this study.

The Langmuir isotherm model assumes that monolayer adsorption takes place on homogeneous surface without

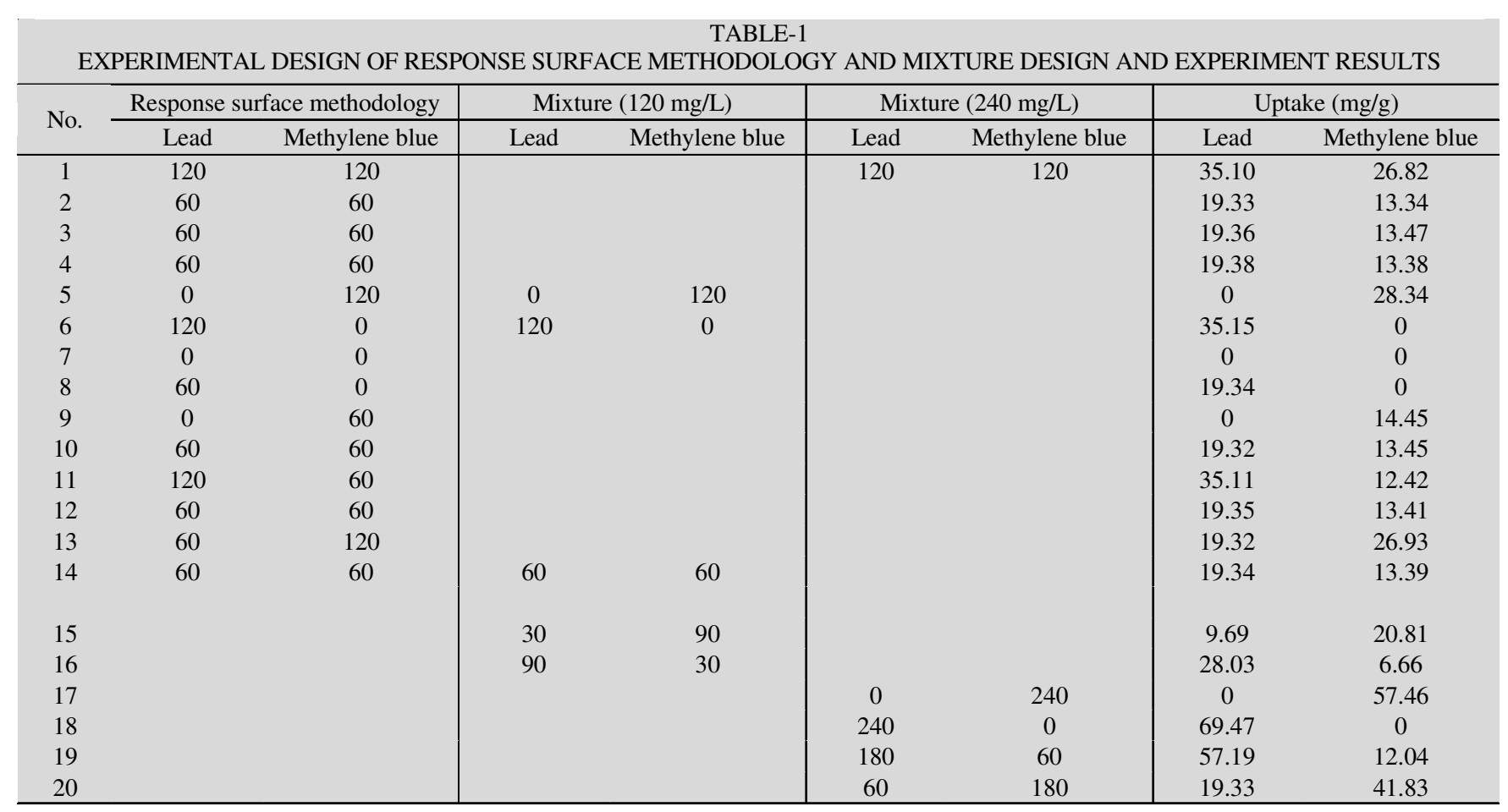


interaction between the adsorbed molecules ${ }^{9}$. The linear form of this model is expressed as eqn. 3 :

$$
\frac{\mathrm{C}_{\mathrm{e}}}{\mathrm{q}_{\mathrm{e}}}=\frac{1}{\mathrm{q}_{\mathrm{m}} \mathrm{K}_{\mathrm{L}}}+\frac{\mathrm{C}_{\mathrm{e}}}{\mathrm{q}_{\mathrm{m}}}
$$

where $\mathrm{C}_{\mathrm{e}}(\mathrm{mg} / \mathrm{L})$ is the equilibrium concentration of $\mathrm{Pb}(\mathrm{II})$ in the solution; $\mathrm{q}_{\mathrm{e}}(\mathrm{mg} / \mathrm{g})$ is the equilibrium concentration of $\mathrm{Pb}$ (II) on the adsorbent; $\mathrm{q}_{\mathrm{m}}(\mathrm{mg} / \mathrm{g})$ is the maximum monolayer adsorption capacity and $\mathrm{K}_{\mathrm{L}}(\mathrm{L} / \mathrm{mg})$ is the Langmuir model constant related to the heat of adsorption.

Freundlich isotherm model supposes that the adsorption takes place on heterogeneous surfaces with the interaction between the adsorbed molecules ${ }^{10}$. The linear form of model can be express by following equation:

$$
\ln \mathrm{q}_{\mathrm{e}}=\ln \mathrm{K}_{\mathrm{F}}+(1 / \mathrm{N})\left(\ln \mathrm{C}_{\mathrm{e}}\right)
$$

where $K_{F}$ and $N$ are the Freundlich constants; $K_{F}[\mathrm{mg} / g$ $\left.(\mathrm{L} / \mathrm{mg})^{1 / \mathrm{N}}\right]$ is the adsorption capacity; the value of $1 / \mathrm{N}$ is smaller than one indicates a favourable adsorption process.

Temkin isotherm model considers that the heat of adsorption of all the molecules would decrease linearly with coverage by the effects of some indirect interaction between adsorbent and adsorbate ${ }^{11}$. And linear form of Temkin model expresses as eqn. 5 :

$$
\mathrm{q}_{\mathrm{e}}=(\mathrm{RT} / \mathrm{b}) \ln \left(\mathrm{K}_{\mathrm{T}} \mathrm{C}_{\mathrm{e}}\right)
$$

where $b$ is the Temkin isotherm constant and $K_{T}(\mathrm{~L} / \mathrm{mg})$ is the Temkin isotherm energy constant; $\mathrm{R}$ is the universal gas constant $(8.314 \mathrm{~J} / \mathrm{mol})$; $\mathrm{T}(\mathrm{K})$ is the absolute temperature.

The analysis of adsorption isotherms was performed by using initial lead and methylene blue concentration from 20 to $120 \mathrm{mg} / \mathrm{L}$ at $25^{\circ} \mathrm{C}$. The constants and correlation coefficients of three isotherm models were given in Table-2. As shown, the adsorption isotherm of lead on $O$. radicata, no matter in single or mixture system, were better fitted to Freundlich isotherm. The $\mathrm{R}^{2}(0.968,0.952)$ of Freundlich are higher than $R^{2}(0.962,0.935)$ of Langmuir and $R^{2}(0.962$, 0.903 ) of Temkin. It suggested that the adsorption of lead took place on heterogeneous surface of adsorbent. The adsorption isotherm of methylene blue on $O$. radicata, in single system, the $\mathrm{R}^{2}$ was too low to fit with no isotherm model, but in mixture system, the adsorption process was fitted with Freundlich model. The $\mathrm{R}^{2}(0.952)$ of Freundlich model was higher than other two models.

Adsorption kinetics: To investigate the adsorption kinetic pattern of lead and methylene blue on $O$. radicata, three popular models are applied in this study.
The linear forms of the pseudo-first-order model (eqns. 6) ${ }^{12}$ and the pseudo-second-order model (eqn. 7) ) $^{13}$ can be described as follows, respectively:

$$
\begin{gathered}
\ln \left(\mathrm{q}_{\mathrm{e}}-\mathrm{q}_{\mathrm{t}}\right)=\ln \mathrm{q}_{\mathrm{e}}-\mathrm{K}_{1} \mathrm{t} \\
\frac{\mathrm{t}}{\mathrm{q}_{\mathrm{t}}}=\frac{1}{\mathrm{~K}_{2} \mathrm{q}_{\mathrm{e}}^{2}}+\frac{\mathrm{t}}{\mathrm{q}_{\mathrm{e}}}
\end{gathered}
$$

where $\mathrm{q}_{\mathrm{e}}(\mathrm{mg} / \mathrm{g})$ and $\mathrm{q}_{\mathrm{t}}(\mathrm{mg} / \mathrm{g})$ are amount of $\mathrm{Pb}(\mathrm{II})$ adsorbed on modified spent $L$. edodes at equilibrium time and time $\mathrm{t}$ ( $\min )$, respectively. $\mathrm{K}_{1}\left(\mathrm{~min}^{-1}\right)$ and $\mathrm{K}_{2}(\mathrm{~g} / \mathrm{mg} \min )$ are the pseudo-first-order and the pseudo-second-order rate constants, respectively.

The Elovich model ${ }^{14}$ is common used to describe chemisorption, expressing as following form:

$$
\mathrm{q}_{\mathrm{t}}=(1 / \mathrm{y}) \ln (\mathrm{xy})+(1 / \mathrm{y}) \ln \mathrm{t}
$$

where $\mathrm{x}(\mathrm{mg} / \mathrm{g}$ min) is the initial adsorption rate and $\mathrm{y}(\mathrm{g} / \mathrm{mg})$ is the desorption constant.

All the parameters of three adsorption kinetic models were shown in Table- 3 . According to the $\mathrm{R}^{2}$ values, it indicated that the adsorption of lead and methylene blue on $O$. radicata couldn't be well described by the pseudo-first-order model. Whereas, it can be seen from Fig. 1 that the pseudo-secondorder kinetic linear model could give an ideal fit to the experimental data, for the $\mathrm{R}^{2}$ of lead is 0.9982-0.9997 in single and mixture system, especially, for the $\mathrm{R}^{2}$ of methylene blue is 1.0000. Moreover, that the calculated $\mathrm{q}_{\mathrm{e}}$ was so close to the experimental data also suggested a good agreement. Fig. 2 showed that the data of methylene blue both in single and mixture system were also fitted well to Elovich kinetic model. It is suggested that the adsorption process of methylene blue was chemical adsorption.

\section{Conclusion}

In this study, the $O$. radicata was used as an adsorbent for removal of lead and methylene blue from aqueous solution. When adsorption of lead and methylene blue in mixture wastewater, it is found that the presence of lead could inhibit the adsorption of methylene blue and with the initial concentration of lead increase, the inhibition was increased too. The isotherm and kinetic analysis were carried out and the results suggested that the adsorption of lead in both single and mixture system were followed the Freundlich model, illustrating that the adsorption of lead on $O$. radicata was heterogeneous adsorption. The adsorption of methylene blue in single system did not fit with any of the three models, but the data of methylene

TABLE-2

LEAD, METHYLENE BLUE SINGLE-SYSTEM AND MIXTURE-SYSTEM ADSORPTION ISOTHERMS RESULTS

\begin{tabular}{clcc|cc}
\hline \multirow{2}{*}{ Adsorption isotherms } & \multirow{2}{*}{ Parameter } & \multicolumn{2}{c}{ Single-system } & \multicolumn{2}{c}{ Mixture-system } \\
\cline { 3 - 6 } & & Lead & Methylene blue & Lead & Methylene blue \\
\cline { 2 - 6 } Langmuir & $\mathrm{q}_{\mathrm{m}}(\mathrm{mg} / \mathrm{g})$ & 41.667 & -16.129 & 43.478 & 55.556 \\
& $\mathrm{~K}_{\mathrm{L}}(\mathrm{L} / \mathrm{mg})$ & 0.075 & 0.130 & 0.066 & 0.052 \\
& $\mathrm{R}^{2}$ & 0.962 & 0.504 & 0.935 & 0.603 \\
\hline \multirow{3}{*}{ Freundlich } & $\mathrm{K}_{\mathrm{F}}\left[\mathrm{mg} / \mathrm{g}(\mathrm{L} / \mathrm{mg})^{1 / \mathrm{N}}\right]$ & 5.540 & 1.749 & 5.023 & 3.165 \\
& $\mathrm{~N}$ & 2.123 & 0.585 & 2.020 & 1.290 \\
& $\mathrm{R}^{2}$ & 0.968 & 0.862 & 0.952 & 0.954 \\
\hline \multirow{2}{*}{ Temkin } & $\mathrm{K}_{\mathrm{T}}(\mathrm{L} / \mathrm{mg})$ & 0.780 & 0.627 & 0.663 & 0.796 \\
& $\mathrm{~b}$ & 278.098 & 112.925 & 266.406 & 261.100 \\
& $\mathrm{R}^{2}$ & 0.962 & 0.797 & 0.903 & 0.882 \\
\hline
\end{tabular}


TABLE-3

LEAD, METHYLENE BLUE SINGLE AND MIXTURE SYSTEM ADSORPTION KINETIC RESULTS

\begin{tabular}{|c|c|c|c|c|c|}
\hline \multirow{2}{*}{ Kinetic model } & \multirow{2}{*}{ Parameter } & \multicolumn{2}{|c|}{ Single-system } & \multicolumn{2}{|c|}{ Mixture-system } \\
\hline & & Lead & Methylene blue & Lead & Methylene blue \\
\hline \multirow{3}{*}{ Pseudo-first-order } & $\mathrm{q}_{\mathrm{e}}(\mathrm{cal})(\mathrm{mg} / \mathrm{g})$ & 5.124 & 11.156 & 4.255 & 14.083 \\
\hline & $\mathrm{K}_{1}\left(\min ^{-1}\right)$ & 0.023 & 0.020 & 0.020 & 0.025 \\
\hline & $\mathrm{R}^{2}$ & 0.912 & 0.974 & 0.858 & 0.985 \\
\hline \multirow{4}{*}{ Pseudo-second-order } & $\mathrm{q}_{\mathrm{e}}(\mathrm{cal})(\mathrm{mg} / \mathrm{g})$ & 42.478 & 1000 & 41.667 & 1000 \\
\hline & $\mathrm{K}_{2}(\mathrm{~g} / \mathrm{mg} \min )$ & 0.014 & - & 0.014 & - \\
\hline & I (mg/g min) & 26.316 & - & 25.000 & - \\
\hline & $\mathrm{R}^{2}$ & 0.9982 & 1.000 & 0.9997 & 1.000 \\
\hline \multirow{3}{*}{ Elovich } & $\mathrm{x}(\mathrm{mg} / \mathrm{g} \min )$ & $1.20 \times 10^{6}$ & $4.80 \mathrm{E}+67$ & $1.75 \times 10^{7}$ & $2.56 \mathrm{E}+54$ \\
\hline & y $(\mathrm{mg} / \mathrm{g})$ & 12.017 & 0.273 & 0.524 & 0.236 \\
\hline & $\mathrm{R}^{2}$ & 0.876 & 0.955 & 0.852 & 0.962 \\
\hline $\mathrm{q}_{\mathrm{e}}(\exp )(\mathrm{mg} / \mathrm{g})$ & & 43.085 & 584.76 & 39.907 & 547.18 \\
\hline
\end{tabular}
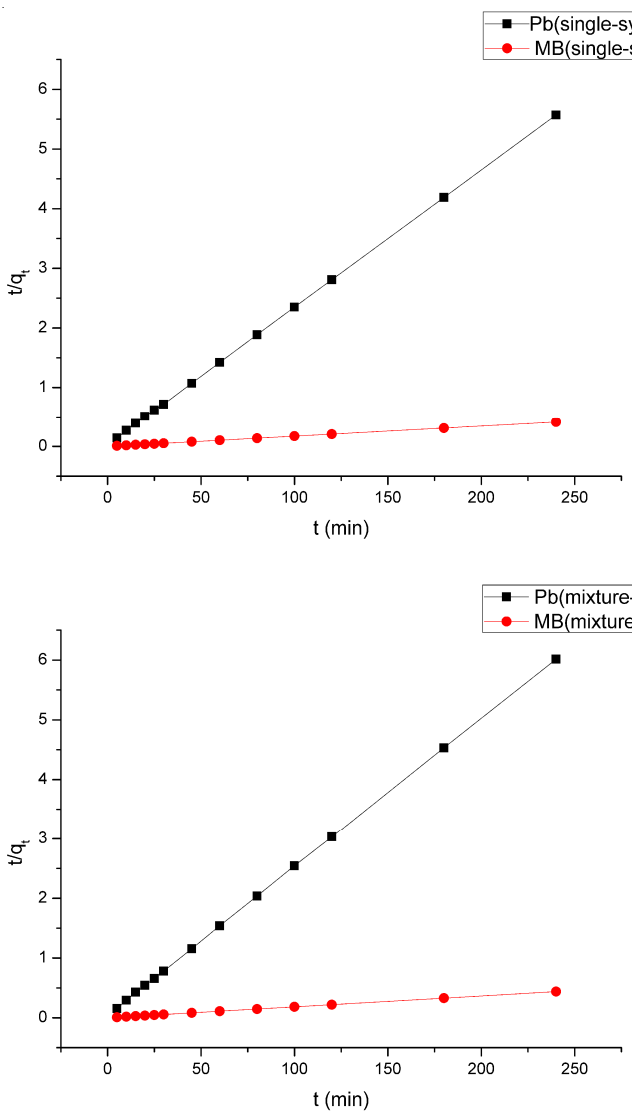

Fig. 1. Linear-fitting of pseudo-second-order model

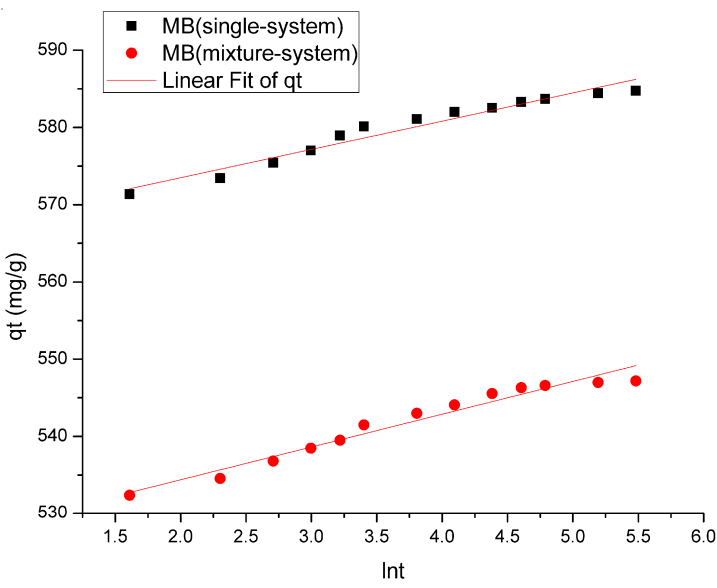

Fig. 2. Linear-fitting of Elovich model blue in mixture system fitted with Freundlich model too. The results of kinetic analysis showed that the adsorption process of lead and methylene blue in single and mixture system all fitted well with pseudo-second-order kinetic model. The adsorption of methylene blue also followed Elovich kinetic model, suggesting that the adsorption process of methylene blue was chemical adsorption.

\section{ACKNOWLEDGEMENTS}

This study was financially supported by the National 863 High Technology Research and Development Program of China (NO.2006AA06Z361), Science and Technology Supportive Project of Sichuan Province, China (NO.2013SZ0062), and Science and Technology Supportive Project of Chengdu (No.12DXYB087JH-005). The authors thank Prof. Guanglei Cheng and Dong Yu from Sichuan University for their technical assistance.

\section{REFERENCES}

1. Y.-R. Cao, Z. Liu, G.-L. Cheng, X.-B. Jing and H. Xu, Chem. Eng. J., 164, 183 (2010).

2. X.L. Tian, C. Li, H.J. Yang, Z.X. Ye and H. Xu, Desalination Water Treat., 27, 319 (2011).

3. M.S. Saja, C.H. Chia, S. Zakaria, S.M. Jani, M.K. Ayob, K.L. Chee, P.S. Khiew and W.S. Chiu, Bioresour. Technol., 102, 7237 (2011).

4. Y.Y. Liu, Q.Q. Zhao, G.L. Cheng and H. Xu, Chem. Eng. J., 173, 792 (2011).

5. R.P. Han, L.J. Zhang, C. Song, M.M. Zhang, H.M. Zhu and L.J. Zhang, Carbohyd. Polym., 79, 1140 (2010).

6. Y.J. Wu, L.J. Zhang, C.L. Gao, J.Y. Ma, X.H. Ma and R.P. Han, J. Chem. Eng. Data, 54, 3229 (2009).

7. S.B. Wang and E. Ariyanto, J. Colloid. Interface Sci., 314, 25 (2007).

8. F. Gönen and Z. Aksu, J. Hazard. Mater., 172, 1512 (2009).

9. I. Langmuir, J. Am. Chem. Soc., 40, 1361 (1918).

10. K.R. Hall, L.C. Eagleton, A. Acrivos and T. Vermeulen, Ind. Eng. Chem. Fundam., 5, 212 (1966).

11. H.M.F. Freundlich, Z. Phys. Chem., 57A, 365 (1906).

12. M.I. Temkin and V. Pyzhev, Acta Physicochim. USSR, 12, 327 (1940).

13. S. Lagergren, Kung. Sven. Veten. Hand., 24, 1 (1898).

14. G. Mckay and Y.S. Ho, Process Biochem., 34, 451 (1999). 